\title{
Effect of Incorporation of Silver Nanoparticles on the Tensile Bond Strength of a Long term Soft Denture Liner
}

\author{
Sareh Habibzadeh ${ }^{1}$ Arman Omidvaran² \\ ${ }^{1}$ Dental Research Center, Dentistry Research Institute, \\ Department of Prosthodontics, School of Dentistry, International \\ Campus, Tehran University of Medical Sciences, Tehran, Iran \\ ${ }^{2}$ Dentist, Private Practice, Tehran, Iran \\ ${ }^{3}$ Dental Material Research Center, Tehran Dental Branch, Islamic \\ Azad University, Tehran, Iran \\ ${ }^{4}$ Department of Community Oral Health, Research Center for Caries \\ Prevention, Dentistry Research Institute, School of Dentistry, \\ Tehran University of Medical Sciences, Tehran, Iran
}

\author{
Address for correspondence Sareh Habibzadeh, DDS, MSc, \\ Department of Prosthodontics, School of Dentistry, International \\ Campus, Tehran University of Medical Sciences, No. 14 Tohidi Street, \\ Heravi Square, Pasdaran Avenue, Tehran 1667837336, Iran \\ (e-mail: s-habibzadeh@tums.ac.ir; sareh.habibzadeh@gmail.com).
}

Eur J Dent 2020;14:268-273

\begin{abstract}
Keywords

- denture liners

- nanoparticles

- tensile bond strength

Objectives This study aimed at assessing the effect of the addition of silver nanoparticles (SNPs) to a silicone soft liner on its tensile bond strength to denture base resin. Materials and Methods SNPs were added to Mucopren cold cure soft liner in 0 (control), $0.5,1,2$, and $3 \mathrm{wt} \%$ concentrations and bonded in 120 stainless steel molds with processed heat cure acrylic resin blocks. Liner/resin combination samples were divided into two groups. The first half was stored for 2 days in distilled water at $37^{\circ} \mathrm{C}$ and then subjected to tensile bond strength, while the other half were thermocycled 3000 times before testing. Mean bond strength, expressed in mega pascals (MPa), was determined in the tensile test with the use of a universal testing machine at a crosshead speed of $5 \mathrm{~mm} / \mathrm{min}$.

Statistical Analysis Data were analyzed using SPSS via one-way analysis of variance test, $t$-test, and Tukey's posthoc, at a 95\% confidence level $(p<0.05)$.

Results Addition of SNPs and thermocycling both caused a significant reduction in the tensile bond strength of Mucopren to acrylic resin; however, in the thermocycled group, the bond strength increased with the increase in the concentration of SNPs $(p<0.001)$.

Conclusion Addition of SNPs to Mucopren soft silicone liner reduces its tensile bond strength to denture acrylic resin.
\end{abstract}

\section{Introduction}

Soft liners are mainly used in removable prostheses to obtain ideal denture fit, conditioning the traumatized tissues beneath the denture base and enhancing the retention of intraoral and extraoral prostheses. ${ }^{1}$ They are described as a class of resilient material used to reline denture base surfaces in contact with the occlusal stress-bearing oral mucosa. ${ }^{2}$ Clinical success with these materials depends on their ability to reshape and adapt to the residual ridge after the application of occlusal loads. ${ }^{3}$ This inherent property makes them suitable for oral diagnostic and therapeutic purposes and an essential adjunct for the treatment of traumatized oral mucosa. ${ }^{1}$ Soft liners are divided into two groups based on their composition: plasticized acrylics and silicone elastomers. Both types are available in autopolymerized and heat-polymerized forms. ${ }^{4}$ In silicone elastomers, no plasticizer is necessary to produce a softening effect; therefore, they keep their properties for a longer period in contrast to the short-term ones who are mostly referred to as tissue
License terms

()(1) $\Theta \circledast$ 
conditioners. ${ }^{1}$ Patients with thin and sharp alveolar ridges, extensive ridge resorption, and severe bony undercuts, are the main candidates for long-term soft liners. ${ }^{1}$

Despite their advantages, the use of soft denture liners is associated with several problems such as loss of softness, water absorption, colonization by Candida albicans, difficulty in cleaning, and adhesion failure from the denture base. ${ }^{4}$ Recently, attention was directed toward the incorporation of nanoparticles such as $\mathrm{Ag}, \mathrm{ZnO}, \mathrm{TiO}_{2}$, and $\mathrm{SiO}_{2}$ into dental materials to improve their properties. ${ }^{5}$ It was reported that the addition of silver nanoparticles (SNPs) in various concentrations enhances the antifungal properties of both denture base and soft liners. ${ }^{6,7}$ Addition of low concentrations of nano- $\mathrm{SiO}_{2}$ to acrylic denture base was reported to be a promising method for improving denture longevity and repair strength. ${ }^{8}$ The SNPs' incorporation within the acrylic denture base material was even stated to improve its viscoelastic properties. ${ }^{9}$

Adequate bonding of soft liners to the acrylic denture bases is essential to ensure their performance. ${ }^{1}$ When liners peel off the resin surface, a potential gap for bacterial growth and biofilm formation is made; therefore, clinical failures with these materials are often attributed to the loss of bonding. ${ }^{10}$ Despite the positive antimicrobial results of the incorporation of antifungals into soft lining materials, adverse effects are reported on their structural properties and especially tensile strength. ${ }^{11-13}$ Studies also showed that the addition of SNPs significantly reduces the compressive, tensile, and flexural strength of acrylic resin, ${ }^{14-16}$ although the authors identified no information in the literature regarding the effects of addition of SNPs to soft liners.

On the other hand, liners are routinely subjected to thermal stresses in the oral cavity, especially during the ingestion of hot and cold foods and beverages, and this can further affect the bond between these materials and denture base resins. ${ }^{4,17}$ Thermocycling has been suggested as an efficient method to mimic the natural aging process of dental restorations ${ }^{18}$ Therefore, this study aimed at assessing the effect of the addition of SNPs to Mucopren soft silicone liner material on its tensile bond strength to denture acrylic resin.

\section{Materials and Methods}

\section{Preparation of PMMA Specimens}

A two-compartment mold stainless steel (length: $65 \mathrm{~mm}$, width: $22 \mathrm{~mm}$, height: $15 \mathrm{~mm}$ ) was prepared by laser cutting and used to fabricate 120 acrylic blocks (Acropars; Tehran, Iran) by the lost wax technique. ${ }^{19}$ The mold was lubricated with petroleum jelly (Vaseline; Unilever, Rotterdam, Netherlands). Cerewax (Istanbul, Turkey) was melted in a heater (Sunburst; New York, USA) and poured into the mold. After 15 minutes, the two compartments of the mold were separated and the wax pattern was removed and placed in $20^{\circ} \mathrm{C}$ water to prevent the dimensional changes. ${ }^{20,21}$ Each wax pattern was divided into two equal halves measuring $8 \times 8 \times 20 \mathrm{~mm}$ to create a $4 \mathrm{~mm}$ thickness of liner between the two acrylic blocks ${ }^{20}$ ( - Fig. 1). $1200 \mathrm{~g}$ volume brass flasks (SongYoung; Taipei, Taiwan) were used, each containing
8 wax patterns. ${ }^{22}$ Heat-cured acrylic resin (Acropars; Tehran, Iran) with a powder liquid ratio of 3:1 was prepared according to the manufacturer's instructions and after trial packing (under 3000 Psi hydraulic press) (Mehrdent; Karaj, Iran), baked at $70^{\circ} \mathrm{C}$ in water for 9 hours. ${ }^{23,24}$

\section{Preparation of SNP Incorporated Soft Liner}

The soft liner selected in this study was Mucopren (Mucopren; Kettenbach, Germany) autocure silicone long-term liner supplied as two pastes ( $\boldsymbol{- F i g . ~ 2 ) . ~ T h e ~ b a s e ~ a n d ~ t h e ~ c a t a l y s t ~ w e r e ~}$ injected equally by an injection gun (Applyfix; Kettenbach, Germany) on two separate pads. The base, catalyst, and pad were separately weighed by a digital scale $(0.000 \mathrm{gr}$; Kern, Germany). SNPs (Nanoshel; $80-100 \mathrm{~nm}$ in size, $99.9 \%$ purity) in $0.5,1,2$, and $3 \mathrm{wt} \%,{ }^{6}$ were weighted and mixed first with the base of the soft liner for 100 seconds, and then the mixture was added to the catalyst and mixed for another 60 seconds. To assess the quality of mixing and ensure adequate dispersion of SNPs, transverse sections were made from the $0.5 \mathrm{wt} \%$ samples by cutting and tearing, and evaluated under a scanning electron microscope (SEM; KYKY-EM3200, KYKY Technology; Shanghai, China).

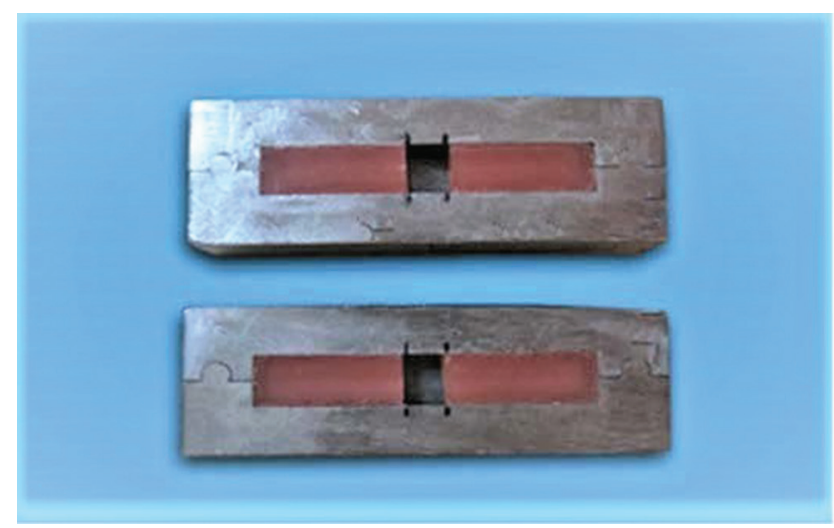

Fig. 1 Stainless steel mold and wax pattern.

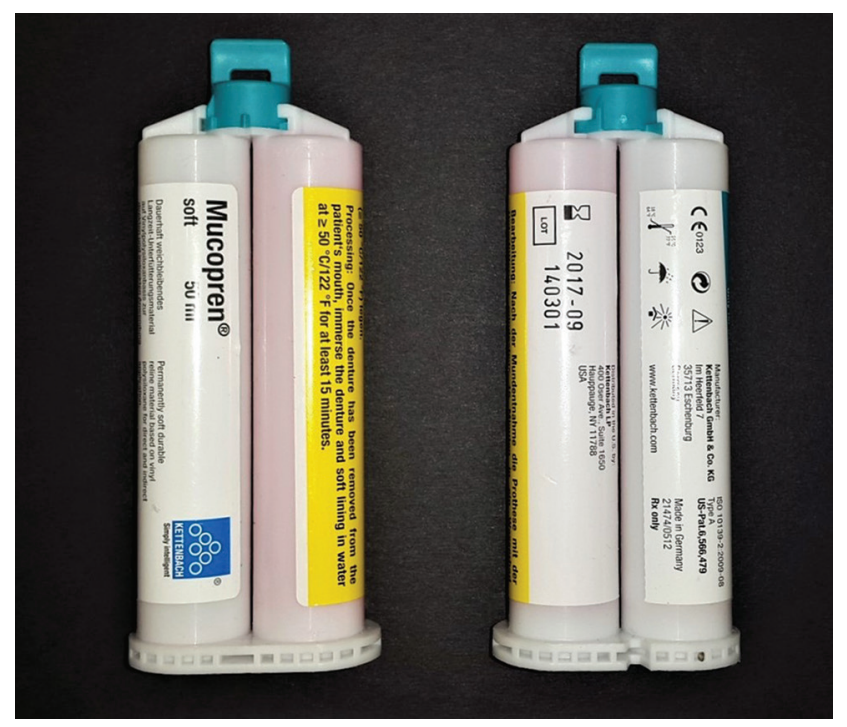

Fig. 2 Mucopren auto cure silicone long-term liner supplied as two pastes. 
Stainless steel molds were lubricated with petroleum jelly, and acrylic blocks were placed in them. Mucopren bonding agent (Panasil; Kettenbach, Eschenburg, Germany) was applied on the acrylic surface, according to the manufacturer's instructions. One layer was applied first and the second layer after one minute and allowed to dry for 30 seconds. ${ }^{25}$ Using a $3 \mathrm{~mL}$ volume syringe (Medoroux; London, UK), the soft liner was injected into the space between the acrylic blocks. To create a smooth surface, a thin glass slide (Mingzhu; Zhejiang, China) measuring $22 \times 22 \times 13 \mathrm{~mm}$ was placed over the blocks, allowing 10 minutes for the complete set. The acrylic blocks/soft liner combination was removed from the mold and incubated at $37^{\circ} \mathrm{C}$ for 2 days.

\section{Tensile Testing and Aging Procedure}

After two days, 60 samples were subjected to the tensile bond strength test at a crosshead speed of $5 \mathrm{~mm} /$ minute using a universal testing machine (Bongshin; Seongnam, Korea) (-Fig. 3). ${ }^{26}$ The remaining 60 samples were subjected to 3000 thermal cycles (Dorsa; Karaj, Iran) in 5 and $55^{\circ} \mathrm{C}$ temperatures with a dwell time of 30 seconds $^{27}$ before the tensile bond strength test ( $\boldsymbol{- \text { Fig. }} \mathbf{4}$ ). For each specimen, the maximum tensile strength before failure was recorded, and the bond strength was calculated using the following equation:

$$
\text { Tensile bond strength }=\frac{\text { Tensile bond strength }}{\text { Cross sectional are }\left(\mathrm{mm}^{2}\right) \text { of the interface }}
$$

Data were summarized as mean and standard deviation. As the interaction effect of SNP concentrations and thermocycling on tensile bound strength became significant, data was analyzed by one-way analysis of variance (ANOVA) (SNPs

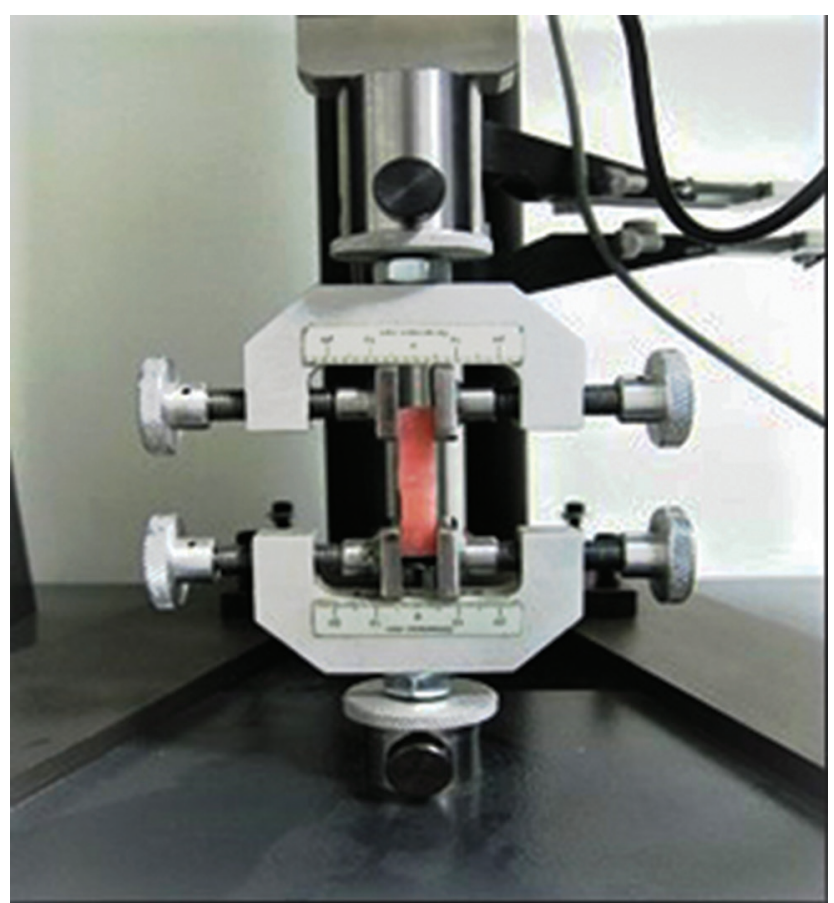

Fig. 3 Microtensile bond strength test, using the universal testing machine.

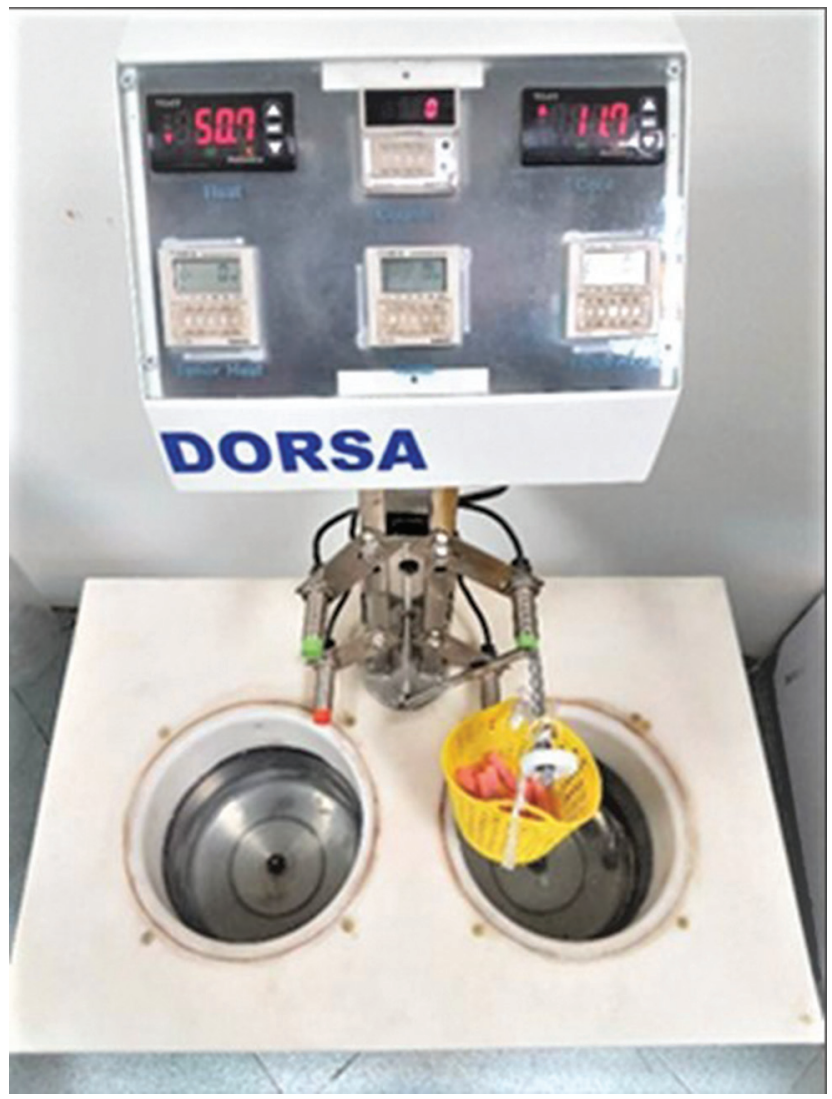

Fig. 4 Thermocycling machine $\left(3000\right.$ thermal cycles in 5 and $55^{\circ} \mathrm{C}$ temperatures with a dwell time of 30 seconds).

concentration and thermocycling) and independent $t$-test using SPSS version 22. One-way ANOVA (followed by Tukey's multiple comparison test) was carried out to assess the effect of the addition of different concentrations of SNPs on tensile bond strength in thermocycled and nonthermocycled groups. Independent $t$-test was performed to compare the effect of thermocycling in each SNP concentration. $p<0.05$ was considered statistically significant.

\section{Results}

According to - Table 1 in the nonthermocycled group, the addition of SNPs in all concentrations decreased the tensile bond strength $(p<0.001)$. However, in the thermocycled group, the addition of SNPs had an inverse effect on the tensile bond strength and by an increase in the concentration of SNPs, the tensile bond strength increased.

Thermocycling in 0 (control) and $1 \mathrm{wt} \%$ SNP groups caused a significant reduction in the bond strength compared with the nonthermocycled group $(p<0.001)$. The same results were obtained in $2 \mathrm{wt} \%(p<0.001)$ and $3 \mathrm{wt} \%(p=0.02)$ SNP groups. Therefore, the effect of thermocycling on the tensile bond strength was also significant in all concentrations and the tensile bond strength of the nonthermocycled group was significantly higher than that of the thermocycled group $(p<0.001)$. 
Table 1 Effect of addition of SNPs on tensile bond strength of soft liner to acrylic resin in thermocycled and nonthermocycled groups

\begin{tabular}{|l|l|l|l|l|l|}
\hline $\begin{array}{l}\text { Concentration } \\
(\text { wt } \%)\end{array}$ & $\begin{array}{l}\text { Mean bond } \\
\text { strength without } \\
\text { thermocycling in } \\
\text { MPa }\end{array}$ & $\begin{array}{l}\text { Mean bond } \\
\text { strength with } \\
\text { thermocycling in } \\
\text { MPa }\end{array}$ & $\begin{array}{l}\text { Mean } \\
\text { difference }\end{array}$ & 95\% confidence & $p$-Value \\
\hline 0 & $1.19 \pm 0.12$ & $0.32 \pm 0.07$ & -0.87 & $-0.96--0.78$ & $<0.001$ \\
\hline 0.5 & $1.05 \pm 0.16$ & $0.38 \pm 0.11$ & -0.68 & $-0.79--0.56$ & $<0.001$ \\
\hline 1 & $0.97 \pm 0.11$ & $0.45 \pm 0.08$ & -0.52 & $-0.60--0.43$ & $<0.001$ \\
\hline 2 & $0.84 \pm 0.11$ & $0.43 \pm 0.07$ & -0.41 & $-0.32--0.49$ & $<0.001$ \\
\hline 3 & $0.60 \pm 0.11$ & $0.50 \pm 0.08$ & -0.11 & $-0.19--0.02$ & 0.02 \\
\hline
\end{tabular}

Abbreviation: SNP, silver nanoparticles.

\section{Discussion}

Difficulty in cleaning makes soft liners susceptible to plaque accumulation. ${ }^{28-31}$ Soft liners are even more susceptible to plaque accumulation and fungal infection than hard liners and acrylic denture bases. ${ }^{5-8}$ To prolong the clinical longevity of these materials and reduce the possibility of biofilm

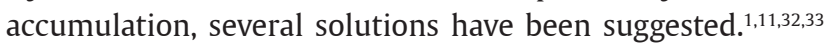
Researchers have attempted to add antimicrobial and antifungal agents to the composition of liners. ${ }^{10,11,32-35}$ Antifungals such as nystatin and fluconazole with different percentages and forms (powder and suspension) have been added to soft liners and have shown positive results, ${ }^{33}$ although there is no agreement on the routine application of these materials. ${ }^{33,34}$ Silver and its compounds have long been used as antibacterial agents due to their biocompatibility and low toxicity. ${ }^{35}$ Advances in science and nanotechnology resulted in the introduction of SNPs. ${ }^{35,36}$ Although studies have discussed the addition of SNPs on the compressive, tensile, and flexural strength of acrylic resin, ${ }^{9,14-16}$ no previous study investigated the effect of addition of SNPs in a soft silicone liner on its tensile bond strength to denture acrylic resin. The results of the current study showed that by an increase in the concentration of SNPs from 0 to $3 \mathrm{wt} \%$, tensile bond strength to acrylic resin decreased. Besides, thermocycling decreases tensile bond strength. However, despite an overall reduction in the tensile bond strength of specimens subjected to thermocycling, tensile bond strength increased with an increase in the concentration of SNPs $(p<0.001)$.

Haghgoo et al evaluated the effect of the addition of different concentrations of SNPs $(20,40,80,100$, and $200 \mathrm{ppm})$ on mechanical properties of resin-modified glass ionomer and indicated an increase in the compressive and flexural strength after 1 day and 1 month compared with the controls. However, the physical properties were found to be lower than the baseline after 4 months. ${ }^{37}$ In a study by Ghaffari et al, the addition of 5\% SNPs caused a reduction in the tensile strength of polymethyl methacrylate in denture base. ${ }^{14}$ Addition of 0.2 and $0.05 \%$ of SNPs to orthodontic two different acrylic resins (Rapid Repair and Selecta Plus) also caused a reduction in their flexural strength. ${ }^{16}$

The properties of polymer nanocomposites depend on the type of incorporated nanoparticles, their size and shape, as well as the concentration and interaction with the polymer matrix ${ }^{38}$. It has been stated that the incorporation of nanoparticles into polymerized dental materials causes these particles to aggregate. The resulting compounds can act as stress-concentrating centers in the matrix of the polymerized material and adversely affect the mechanical properties. ${ }^{39}$ Moreover, studies documented that inorganic materials such as SNPs do not stablish a chemical bond to polymerized materials. ${ }^{14}$ Therefore, the absence of a chemical bond between inorganic silver particles and silicone structure of the soft liner may be another reason for the reduction in tensile bond strength. Others suggested that reduction in the bond strength, following the addition of SNPs, may be due to the irregularities created in the hybrid layer at the interface of the soft liner and acrylic resin, which can create a place for stress accumulation, and negatively affect the mechanical properties of the bond interface. ${ }^{14}$

Long-term soft denture lining (LTSDL) materials constitute a group of polymer materials supplied as two pastes. The catalyst paste is a mixture of vinyl-terminated polydimethylsiloxanes with a platinum catalyst, and the base paste consists of vinyl-terminated polydimethylsiloxanes with hydride-terminated polydimethylsiloxanes. SLTSDLs can be cured in the mouth due to the low temperature required for their cross-linking, and thus called "chair-side" SLTSDLs. The curing reaction does not produce any byproducts and in practice, their use can extend to several months or even years as reported 12 months for Mucopren. ${ }^{40}$ Although sometimes recalled as permanent liners, ${ }^{40}$ the use of any dental restorative material suffers an inherent problem of aging that develops over time. ${ }^{41}$ Thermocycling is conventionally performed for fast thermal aging and simulation of thermal conditions in the oral cavity. ${ }^{42}$ The effect of thermocycling on physical properties of soft liners such as tensile and shear bond strength has been evaluated in previous studies and nearly all have agreed on its negative effect.,17,26,42,43 Ozkan et al evaluated the effect of thermocycling on tensile bond strength of six resin-based liners and reported that except for Ufigel and Mollosil liners, thermocycling decreased the tensile bond strength of other liners. ${ }^{43}$ In a study by Elias et al on three silicone soft liners, Mucopren showed the highest tensile bond strength before thermocycling, compared with the 
other types. However, in general, the tensile bond strength of all three silicone liners was significantly reduced following thermocycling. ${ }^{26}$ The ISO/TR 11450 standard indicates that a thermocycling regimen comprising 500 cycles in water between 5 and $55^{\circ} \mathrm{C}$ is an appropriate artificial aging test. ${ }^{44}$ In this study, 3000 cycles equivalent to 12 months of clinical usage ${ }^{33}$ were preformed which corresponds well to the life span of Mucopren. Our results regarding the effect of thermocycling on tensile bond strength were in line with previous studies, confirming that tensile bond strength decreases after thermal aging.

Reduction in the tensile bond strength, following thermocycling, may be due to the immersion of soft liner in water. When immersed in water, plasticizers are released and water sorption occurs. Water penetrates the interface of soft liner and denture resin base and causes edema and stress in the region. This changes the viscoelastic properties of the soft liner and its hardening. Therefore, instead of cushioning effect, it directly transfers external loads to the acrylic interface and decreases the resistance of interface to degradation and fracture. ${ }^{26}$ Water sorption is, however, less in silicone liners compared with acrylic ones. ${ }^{1}$ Szakonyi et al reported that water sorption can cause material degradation at the molecular level. The level of degradation depends on the volume of water absorbed and solid state of the object. ${ }^{45}$ Therefore, the increasing trend of bond strength after thermocycling by an increase in the concentration of SNPs in our study may be explained by the fact that thermocycling results in water sorption, and since silver is solid, it would have the highest effect on the highest concentrations, causing degradation of silver. As a result, the free silver acts as a filler in the matrix of the soft liner and increases the bond strength.

The current study used $0.5,1,2$, and 3 wt\% SNPs, which were the more common concentrations of SNP in previous studies. ${ }^{16}$ The $3 \mathrm{wt} \%$ concentration of SNPs showed the least changes in tensile bond strength after thermocycling. As the minimum acceptable clinical threshold of tensile bond strength of soft liner to denture acrylic resin is $0.44 \mathrm{MPa},{ }^{46}$ the $3 \mathrm{wt} \% \mathrm{SNP}$ incorporation to Mucopren might provide the best clinical results.

Addition of SNPs may increase toxicity of the materials, and there exist concerns regarding the release of this material in the oral cavity and its absorption. ${ }^{5}$ Therefore, whether this combination (Mucopren + SNP) confers high antifungal properties while maintaining optimal biocompatibility needs to be further investigated clinically.

It is difficult to obtain a homogenous dispersion of filler (nanoparticles) without aggregations in laboratory level, and this can reduce the expected effects of the filler addition. Therefore, commercial mixing machines and mechanicalelectric mixers, vacuum, and high-shear action are suggested to be used in future studies to improve the incorporation of fillers and allow trapped air and large aggregations to be eliminated. The dimensional stability of the wax patterns and acrylic blocks was extremely important to be taken care of in this study. Finally, the authors investigated the tensile bond strength of Mucopren soft liner, yet other properties of this material such as the flexural strength, color stability, solubility, viscoelasticity, and odor need to be addressed in future studies.

\section{Conclusion}

Within the limitations of this study, the results showed that the addition of $0.5,1,2$, and 3 wt\% SNPs to Mucopren soft liner reduced its tensile bond strength to denture acrylic resin. Thermocycling (simulating one year of clinical service) decreased the tensile bond strength of soft liner to denture acrylic resin. Therefore, SNP addition to Mucopren soft silicone liner to improve its antifungal properties may adversely affect its tensile bond strength to denture acrylic resin.

\section{Conflict of Interest \\ None declared.}

\section{Acknowledgments}

This work was based on the thesis submitted to the School of Dentistry, Tehran University of Medical Sciences, International Campus, in partial fulfillment of the doctorate degree in dentistry.

\section{References}

1 Zarb G, Hobkirk J, Eckert S, Jacob R, Prosthodontic Treatment for Edentulous Patients Complete Dentures and ImplantSupported Prostheses. 13th ed. St. Louis: Mosby; 2013 145-149

2 Sánchez-Aliaga A, Pellissari CV, Arrais CA, Michél MD, Neppelenbroek KH, Urban VM. Peel bond strength of soft lining materials with antifungal to a denture base acrylic resin. Dent Mater J 2016;35(2):194-203

3 Garcia LT, Jones JD. Soft liners. Dent Clin North Am 2004;48(3):709-720

4 Pinto JR, Mesquita MF, Henriques GE, de Arruda Nóbilo MA. Effect of thermocycling on bond strength and elasticity of 4 long-term soft denture liners. J Prosthet Dent 2002;88(5):516-521

5 Schmalz G, Hickel R, van Landuyt KL, Reichl FX. Scientific update on nanoparticles in dentistry. Int Dent J 2018;68(5):299-305

$6 \mathrm{Nam}$ KY. In vitro antimicrobial effect of the tissue conditioner containing silver nanoparticles. J Adv Prosthodont 2011;3(1):20-24

7 Wady AF, Machado AL, Zucolotto V, Zamperini CA, Berni E, Vergani CE. Evaluation of Candida albicans adhesion and biofilm formation on a denture base acrylic resin containing silver nanoparticles. J Appl Microbiol 2012;112(6):1163-1172

8 Gad MM, Abualsaud R, Al-Thobity AM, et al. Effect of SiO2 nanoparticles addition on the flexural strength of repaired acrylic denture base. Eur J Dent 2020;14(1):19-23

9 Mahross HZ, Baroudi K. Effect of silver nanoparticles incorporation on viscoelastic properties of acrylic resin denture base material. Eur J Dent 2015;9(2):207-212

10 Neppelenbroek KH, Lima JFM, Hotta J, Galitesi LL, Almeida ALPF, Urban VM. Effect of incorporation of antifungal agents on the ultimate tensile strength of temporary soft denture liners. J Prosthodont 2018;27(2):177-181

11 el-Charkawi H, el-Said EA, Safouh HM, el-Raghi N. Effect of addition antimicrobial agents to denture reliners. Egypt Dent J 1994;40(3):785-790

12 Urban VM, Seó RS, Giannini M, Arrais CA. Superficial distribution and identification of antifungal/antimicrobial agents 
on a modified tissue conditioner by SEM-EDS microanalysis: a preliminary study. J Prosthodont 2009;18(7):603-610

13 Urban VM, de Souza RF, Arrais CA, Borsato KT, Vaz LG. Effect of the association of nystatin with a tissue conditioner on its ultimate tensile strength. J Prosthodont 2006;15(5):295-299

14 Ghaffari T, Hamedi-Rad F. Effect of silver nano-particles on tensile strength of acrylic resins. J Dent Res Dent Clin Dent Prospect 2015;9(1):40-43

15 Ghaffari T, Hamedirad F, Ezzati B. In Vitro comparison of compressive and tensile strengths of acrylic resins reinforced by silver nanoparticles at $2 \%$ and $0.2 \%$ concentrations. J Dent Res Dent Clin Dent Prospect 2014;8(4):204-209

16 Sodagar A, Kassaee MZ, Akhavan A, Javadi N, Arab S, Kharazifard MJ. Effect of silver nano particles on flexural strength of acrylic resins. J Prosthodont Res 2012;56(2):120-124

17 Tugut F, Coskun ME, Dogan DO, Kirmali O, Akin H. Tensile bond strength between soft liners and two chemically different denture base materials: effect of thermocycling. J Prosthodont 2016;25(4):319-323

18 Akin GE, Herguner-Siso S, Ozcan M, Ozel-Bektas O, Akin H. Bond strengths of one-step self-etch adhesives to laser-irradiated and bur-cut dentin after water storage and thermocycling. Photomed Laser Surg 2012;30(4):214-221

19 Rahn AO, Ivanhoe JR, Plummer KD, Textbook of Complete Dentures. 6th ed. Shelton: PMPH-USA; 2009 11-14

20 Surapaneni H, Ariga P, Haribabu R. Ravi Shankar Y, Kumar VH, Attili S. Comparative evaluation of tensile bond strength between silicon soft liners and processed denture base resin conditioned by three modes of surface treatment: an invitro study. J Indian Prosthodont Soc 2013;13(3):274-280

21 Lau M, Amarnath GS, Muddugangadhar BC, Swetha MU, Das KA. Tensile and shear bond strength of hard and soft denture relining materials to the conventional heat cured acrylic denture base resin: an in-vitro study. J Int Oral Health 2014;6(2):55-61

22 Singh N, Khanna PK. In situ synthesis of silver nano-particles in polymethylmethacrylate. Mater Chem Phys 2007;104(2):367-372

23 Mahajan N, Datta K. Comparison of bond strength of auto polymerizing, heat cure soft denture liners with denture base resin - an in vitro study. J Indian Prosthodont Soc 2010;10(1):31-35

24 Morrow RM, Rudd KD, Rhoads JE, Dental Laboratory Procedures: Complete Dentures. 2nd ed. St. Louis: Mosby; 1986 125-140

25 Soratur S, Essentials of Prosthodontics. 1st ed Jaypee Brothers Medical Publishers (P) Ltd: New Delhi, India; 2009 154-180

26 Elias CN, Henriques FQ. Effect of thermocycling on the tensile and shear bond strengths of three soft liners to a denture base resin. J Appl Oral Sci 2007;15(1):18-23

27 Gale MS, Darvell BW. Thermal cycling procedures for laboratory testing of dental restorations. J Dent 1999;27(2):89-99

28 Hahnel S, Rosentritt M, Bürgers R, Handel G, Lang R. Candida albicans biofilm formation on soft denture liners and efficacy of cleaning protocols. Gerodontology 2012;29(2):e383-e391

29 Boscato N, Radavelli A, Faccio D, Loguercio AD. Biofilm formation of Candida albicans on the surface of a soft denture-lining material. Gerodontology 2009;26(3):210-213
30 Pereira-Cenci T, Cury AA, Cenci MS, Rodrigues-Garcia RC. In vitro Candida colonization on acrylic resins and denture liners: influence of surface free energy, roughness, saliva, and adhering bacteria. Int J Prosthodont 2007;20(3):308-310

31 Wright PS, Young KA, Riggs PD, Parker S, Kalachandra S. Evaluating the effect of soft lining materials on the growth of yeast. J Prosthet Dent 1998;79(4):404-409

32 Matsuura T, Abe Y, Sato Y, Okamoto K, Ueshige M, Akagawa Y. Prolonged antimicrobial effect of tissue conditioners containing silver-zeolite. J Dent 1997;25(5):373-377

33 Chopde N, Pharande A, Khade MN, Khadtare YR, Shah SS, Apratim A. In vitro antifungal activity of two tissue conditioners combined with nystatin, miconazole and fluconazole against Candida albicans. J Contemp Dent Pract 2012;13(5):695-698

34 Salim N, Moore C, Silikas N, Satterthwaite JD, Rautemaa R. Fungicidal amounts of antifungals are released from impregnated denture lining material for up to 28 days. J Dent 2012;40(6):506-512

35 Kim JS, Kuk E, Yu KN, et al. Antimicrobial effects of silver nanoparticles. Nanomedicine (Lond) 2007;3(1):95-101

36 Rai M, Yadav A, Gade A. Silver nanoparticles as a new generation of antimicrobials. Biotechnol Adv 2009;27(1):76-83

37 Haghgoo R, Rezvani MB, Kameli S. Effect of various amounts of nanosilver incorporation on the mechanical properties of resin modified glass-ionomer cement. J Dent Med 2013;26(3):211-217

38 Jordan J, Jacob KL, Shart MA. Experimental trends in polymer nano-composites - A review. Mater Sci Eng 2005;393:1-11

39 Sehajpal SB, Sood VK. Effect of metal fillers on some physical properties of acrylic resin. J Prosthet Dent 1989;61(6):746-751

40 Chladek G, Żmudzki J, Kasperski J. Long-term soft denture lining materials. Materials (Basel) 2014;7(8):5816-5842

41 Ferrando-Magraner E, Bellot-Arcís C, Paredes-Gallardo V, et al. Antibacterial properties of nanoparticles in dental restorative materials. A systematic review and meta-analysis. Medicina (Kaunas) 2020;56(2):E55

42 Botega DM, Sanchez JL, Mesquita MF, Henriques GE, Consani RL. Effects of thermocycling on the tensile bond strength of three permanent soft denture liners. J Prosthodont 2008;17(7):550-554

43 Kulak-Ozkan Y, Sertgoz A, Gedik H. Effect of thermocycling on tensile bond strength of six silicone-based, resilient denture liners. J Prosthet Dent 2003;89(3):303-310

44 International Organization for Standardization, ISO TR 11405 , Dental Materials-Guidance on Testing of Adhesion to Tooth Structure. Geneva, ISO; 1994

45 Szakonyi G, Zelkó R. The effect of water on the solid-state characteristics of pharmaceutical excipients: molecular mechanisms, measurement techniques, and quality aspects of final dosage form. Int J Pharm Investig 2012;2(1):18-25

46 Geramipanah F, Ghandari M, Zeighami S. The effect of thermocycling on tensile bond strength of two soft liners. J Dent (Tehran) 2013;10(5):405-410 